\title{
Experience of Drug Abusers Participating in Community-Based Drug Rehabilitation Services Provided by the Counselling Centres for Psychotropic Substance Abusers (CCPSAs) in Hong Kong
}

\author{
Mimi Mei Ha Tiu* ${ }^{(D}$, Carmen Ka Man Fung, Wing Yan Fung, Yin Yee Lai, Chui Man Tse, \\ Tsz Hung Wong, Tsz Kwan Wong, Wing Yi Wong, Mei Suet Wu, Ka Man Yeung, \\ Lok Tung Yeung, Yuk Ying Yu
}

School of Nursing and Health Studies, The Open University of Hong Kong, HKSAR, China

Email: *mhtiu@ouhk.edu.hk

How to cite this paper: Tiu, M.M.H., Fung, C.K.M., Fung, W.Y., Lai, Y.Y., Tse, C.M., Wong, T.H., Wong, T.K., Wong, W.Y., Wu, M.S., Yeung, K.M., Yeung, L.T. and Yu, Y.Y. (2020) Experience of Drug Abusers Participating in Community-Based Drug Rehabilitation Services Provided by the Counselling Centres for Psychotropic Substance Abusers (CCPSAs) in Hong Kong. Health, 12, 1008-1028.

https://doi.org/10.4236/health.2020.128075

Received: July 16, 2020

Accepted: August 14, 2020

Published: August 17, 2020

Copyright (อ 2020 by author(s) and Scientific Research Publishing Inc. This work is licensed under the Creative Commons Attribution International License (CC BY 4.0).

http://creativecommons.org/licenses/by/4.0/

\section{(c) (i) Open Access}

\begin{abstract}
Despite the official statistics showing that the number of drug users has been declining, the problem of drug abuse remains serious in Hong Kong. This problem is evidenced by the trend of hidden and prolonged drug abuse. The recovery of drug abusers is an important process, because the misuse of drugs can cause many bio-psycho-social complications. Therefore, 11 Counselling Centres for Psychotropic Substance Abusers (CCPSAs) in different districts in Hong Kong play an important role on those drug abusers [1]. As a core community-based drug rehabilitation service in Hong Kong, studies about CCPSAs are limited. This study uses a descriptive qualitative approach to explore the experience of drug abusers participating in community-based drug rehabilitation services provided by CCPSAs. Five CCPSA users, who utilized the services for more than two months, participated in the semi-structured face-to-face interviews. Data collected were then analysed by thematic analysis, and five themes were generated: 1) receiving supportive counselling service in CCPSAs, 2) revealing variance towards nonmandatory services in CCPSAs, 3) encountering intrapersonal conflicts when participating in CCPSAs, 4) expanding social network through integration in group activities and 5) wishing to be a companion to other drug abusers. Findings of this study provide valuable insights towards services modification and the enhancement of drug rehabilitation and drug abusers' wellbeing over the collaboration of healthcare workers, services providers and the media. However, this study has some
\end{abstract}


limitations, and it presents suggestions for future research.

\section{Keywords}

Drug Rehabilitation Services, Counselling Centres, Substances Abusers

\section{Introduction}

The problem of drug abuse in Hong Kong remains serious, although the total number of reported drug abusers in the official statistics has been declining in the recent four years [2]. What lies beneath the official statistics is the trend of hidden drug abuse and the associated prolonged drug abuse problems [3]. The troublesome use of drugs brings along bio-psycho-social complications.

The recovery of drug abusers is a complex and chronic process that is liable to relapse. The underlying rationale is that those living in the community who are struggling with drug addiction or have already ceased drug abuse encounter substantial needs and challenges in daily life, and they may be lacking the ability to cope by themselves. Thus, they demand support and assistance from the community. To address their various needs, 11 Counselling Centres for Psychotropic Substance Abusers (CCPSAs) in different districts in Hong Kong play an important role on those drug abusers [1].

CCPSAs are community-based drug rehabilitation services subsidized by Hong Kong Welfare Council; they mainly provide support and assistance to current psychotropic substance abusers at different ages living in the community as well as their family and carers with the goals of achieving the abstinence of drug, sustaining a long-term recovery and developing a healthy lifestyle among those drug abusers through comprehensive assessment and specific interventions. Interventions are associated with various services provided by CCPSAs, such as individual and family counselling, group work, supportive employment, peer counselling and medical support. These services also enable drug abusers to maintain or regain independence and reintegrate into society. Moreover, to achieve early identification and intervention of drug abusers, CCPSAs provide professional training for allied professionals, preventive education programmes to the public and reaching out services to spot out potential drug abusers in the community [4].

However, in view of the current literature, in-depth research on the exact needs and challenges that drug abusers face in the community under Hong Kong cultural discourse is limited. Furthermore, discussion on the quality of CCPSA services is insufficient. Further exploration is needed with its crucialness in modifying the current services for drug abusers in their recovery journey. This study aims to explore the experience of drug abusers participating in community-based drug rehabilitation services provided by CCPSAs, especially on their perception of using the services and the effects brought by the services provided 
by CCPSAs.

\section{Literature Review}

The literature review focused on two major concepts, namely, the challenges that drug abusers face in the community and the community-based rehabilitation services.

\subsection{Challenges of Drug Abusers in the Community}

Drug abusers are those who take chemical substances in a harmful way beyond therapeutic use, which poses a threat to their physical, mental or social wellbeing [5]. In Hong Kong, abused drugs such as narcotic analgesics (e.g. morphine and heroin) and psychotropic drugs (e.g. ketamine and methamphetamine) are common [2]. Drug abusers are usually present with increased drug tolerance; ignorance of daily activities and obligation; and drug dependence, in which they may have a strong desire to take drugs despite the adverse effects [5]. Thus, in the period of transition from drug dependence state to recovery phase, the vulnerability of drug abusers due to their psychosocial complication poses great challenges in the community.

The majority of drug abusers face huge psychological challenges in the community. Several researchers have revealed that drug abusers have a weakened brain response and are vulnerable to emotional stress compared with healthy people [6] [7] [8]. As a result, drug abusers easily experience a lack of self-esteem; feeling doubtful with their own abilities; and a series of unpleasant intrapersonal states, such as hopelessness, frustration and emptiness when facing the uncontrolled and stressful conditions in the community [9] [10] [11] [12] [13]. Therefore, living in the community, especially with strict Chinese ethical norm that values family reputation and dignity [14],drug abusers may lose respect from family, friends and society and also recognition during recovery, which creates considerable personal stress in their daily life [9] [15]. Moreover, drug abusers undergoing treatment services often suffer different levels of psychological distress, such as fear of failing treatment and being seen as a failure [16]. Consequently, numerous studies have collectively discovered that drug craving behaviour may be presented as a way to cope with negative emotions during the recovery, because drugs can reduce tension and the sense of powerlessness and bring pleasure [10] [16] [17].

Moreover, interpersonal stress is usually a challenge that affects drug abusers in the community during their recovery. In family aspect, research has found that most of the drug abusers are heavily affected by unstable family conditions, such as poor attachment with family before or during the course of their addiction; therefore, these influences of unfavourable family environment easily contribute to drug abusers' relapse states when they are living in the community during their recovery [9] [18] [19]. For example, drug abusers experience distrust and suspicion from their family members about their abstinence; with- 
drawal of financial and educational support; and hostility towards them. As a result, drug abusers often use drugs to escape and relieve from these family conflicts [20] [21]. Furthermore, peer relationships maintain considerable influence in the course of recovery. Previous research has consistently reported that delinquent peers can increase the formation of delinquent beliefs and behaviours by reinforcing a peer network environment [22] [23]. Thus, socializing and peer pressure are involved when drug abusers step into the community, which leads to the majority of relapses. Research has found that almost half of relapses involve socializing with pretreatment peers who are also drug abusers [24]. Drug abusers easily form bonding among one another due to similar characteristics; thus, keeping away from their delinquent peers is difficult, and they also struggle forming a supporting and new social network with drug-free peers. Therefore, by the time that they seek treatment in the community, they have limited emotional and financial support from their family, and their social network may consist of largely drug abusers. Thus, family and peer networks are important targets for intervention to reduce the chance of relapse.

In sum, drug abusers face various psychosocial challenges in the community. However, they have insufficient existing resources to handle those challenges that affect their daily lives, and their risk of relapse thus increases [9] [25]. The vulnerability of drug abusers' demands for additional external support and resources to assist them in their recovery in the community is expected.

\subsection{Community-Based Drug Rehabilitation Services}

Community services that address drug abusers' needs are imperative to mobilize to maintain a long-term abstinence of drugs. They play an important role in developing their coping skills and social networks to enhance their resources against situations that lead to the resumption of drug use, as mentioned previously. CCPSAs in Hong Kong provide community-based drug rehabilitation services to assist drug abusers during their recovery [4]. Service users usually approach the centres by themselves or by a professional referral system [26]. Services mainly focus on individual counselling and group treatment, which are commonly mentioned in previous studies [27] [28].

\subsubsection{Individual Counselling}

Individual counselling provides an opportunity for drug abusers to ventilate their feelings and thoughts, discuss their relationship with the substance or the addiction behaviour and sort out and comprehend substances' influences on their life and the lives of people that surround them [29]. The issue of addiction is regarded as the presentation of underlying and unresolved issues that hinder individuals from achieving optimal life and health outcomes [30]. Counsellors assist drug abusers by initially assessing the addiction and personal problems, followed by designing a mutually-agreed, appropriate and individualized service plan to address the problems [29].

Individual counselling also emphasizes on facilitating the clients, in their ca- 
pacity, to address the problems and take actions [27]. This facilitation often involves reshaping one's maladaptive thoughts, emotions and perceptions [31], for example, having a realistic understanding of one's self.

\subsubsection{Group Treatment}

Different forms of group treatment are developed in supplementing individualized approaches and meeting the specific needs of drug abusers during drug recovery [32]. CCPSAs offer peer support groups and life and social development groups.

Peer support groups are pivotal in drug recovery, with growing evidence to help develop stress-coping strategies and psychosocial support. Such groups in the recovery of substance use disorder (SUD) can improve participants' self-efficacy to cope with psychological crises. Positive changes including improvement in negative affect, perceptions towards social support and reduction of feeling shame have been demonstrated [33]. A systematic review about peer recovery service in SUD recovery shows similar findings. It illustrates desirable outcomes of increased treatment retention period, improved social support and relationships with service providers and increased satisfaction with the overall drug treatment experience [28]. Thus, peer support groups play an irreplaceable role along with drug recovery.

Life and social development groups, including social skills training, occupation-oriented groups and interest groups, are provided to develop interests and enhance clients' motivation to abstain [1]. A Danish pilot study found that exercise group intervention increased the fitness level of drug abuser participants, which in turn reduced the suffering feeling from abstinence. Motivation to abstinence is sustained through a group setting [34]. Moreover, patient characteristics are associated with the influence of art and music therapy in drug recovery. Women and adolescents are prone to artistic therapy [35]. In view of cultural differences and individual needs, the effects of life and social development groups to drug abusers in the Hong Kong context is not comprehensively understood.

\section{Aim and Objectives}

This study aims to explore the experience of drug abusers participating in community-based drug rehabilitation services provided by CCPSAs. Its objectives are to 1) explore the service users' perceptions of the community-based drug rehabilitation services provided by CCPSAs and 2) explore the psychosocial influence brought by community-based drug rehabilitation services to drug abusers.

\section{Methods}

\subsection{Research Design}

The research design is a descriptive qualitative study. The qualitative study aims to uncover and understand the experience of participants [36] who are using the 
drug rehabilitation services provided by CCPSAs.

\subsection{Target Population and Sampling}

Purposive sampling was adopted, in which the researchers selected and identified information-rich participants who meet the predetermined criteria of importance [37]. The participants who are willing to share their experiences for this study and have appropriate information were recruited from CCPSAs. The target population 1) had past drug abuse experiences on single or poly drug use without limitation on drug types and length of drug abusing experience; 2) participated in drug treatment and rehabilitative services provided by any CCPSA for more than two months, which in view of the median length of stay for outpatient treatment, is 78 days, as reported by the Treatment Episode Data Set by [38]. Five participants were recruited in the study. The demographic data of the participants is listed in Table 1.

\subsection{Data Collection}

Semi-structured individual interviews were conducted from 2019 to 2020. Before the interview, a semi-structured interview guide was designed; it includes questions that need to be addressed during the interview and ensures all the topics are covered [39]. The sequence of asking questions is flexible to help focus on specific topics [40]. Each face-to-face interview comprised one interviewer and one observer. The duration of interviews lasted from 45 minutes to 1 hour. To ensure right of privacy and limit disturbance, the participants were interviewed in a private room located in the CCPSAs. Written information about the study and interview guide was given to the informants prior to the interview. The interviewer orientated the participants about their rights and introduced the aim of the study at the beginning. Written informed consent was also obtained from participants. All interviews were audio-taped and transcribed verbatim. Voice and tone of speech could be recorded in the transcript to facilitate the closest to the original events [41].

\subsection{Data Analysis}

Thematic analysis was applied in this study. The coding and analysis of data in the analysis process were guided by what the study aims to explore [42]. On this

Table 1. Demographic data of participants.

\begin{tabular}{ccccccc}
\hline No. & Pseudonym & Age & Gender & $\begin{array}{c}\text { Year(s) of } \\
\text { taking drugs }\end{array}$ & $\begin{array}{c}\text { Year(s) of receiving Year(s) of abstinence } \\
\text { CCPSA services }\end{array}$ & \begin{tabular}{c} 
from drugs \\
\hline 01
\end{tabular} \\
& Him & 27 & Male & 9.5 & 1 & 2 \\
02 & Chan & 44 & Male & 10 & 6 & 14 \\
03 & Yu & 30 & Female & 9 & 5 & 6 \\
04 & Sum & 28 & Female & 10 & 3 & 3 \\
05 & Man & 30 & Male & 16 & 5 & 2 \\
\hline
\end{tabular}


basis, one aim and two objectives were set, which helped develop the interview questions for data collection and provided direction for the analysis process. Thematic analysis could also aid in summarizing the main features in data and generating a clear final report, given that the researchers needed to undergo a well-structured approach to interpret the data [43]. The audio content of the interviews was initially transcribed verbatim. Then, the research team familiarized the data by reading and rereading the transcripts. Afterwards, the research team generated initial codes to identify the interesting features of the data set. A code is usually a word or a short phase that assigns symbolic meaning to a set of data [44]. In the following step, code was collated into potential themes. Then, all data relevant to each potential theme were gathered, and the research team reviewed whether the themes are coherent to the coded extracts and the entire data set. Subsequently, the research team generated clear definitions and names for each theme. Lastly, the research team moved on to the final analysis and produced an analysis report.

\section{Results}

Five themes were generated in this study: 1) receiving supportive counselling service in CCPSAs, 2) revealing variance towards nonmandatory services in CCPSAs, 3) encountering intrapersonal conflicts when participating in CCPSAs, 4) expanding social network through integration in group activities and 5) wishing to be a companion to other drug abusers.

\subsection{Receiving Supportive Counselling in CCPSAs}

The support provided by the social workers, including emotional companionship and substantial help, are adequate and important in assisting informants' needs and problems. Two sub-themes emerged from this theme.

\subsubsection{Being Motivated during Counselling}

Continuous processes of individual counselling facilitate motivation and determination. Participants were "nudged" to take actions and make changes in their mentalities.

"It is like being pushed to move. Once you have started, things became easier...to see him (the counsellor) and do as he was told made me want to quit using drugs." (Him)

"Gradually, I understand more about the meaning of life. I started to wish for things in future. And I know more about myself... I cannot tell an exact time point when I decided to quit, it is a slow and gradual process." (Chan)

\subsubsection{Gaining Emotional and Substantial Support from Social Workers}

The participants reported having difficulties in finding suitable listeners to disclose their feelings when they felt upset and lost. CCPSA' individual counselling service provided them a channel to release their emotions. The companionship of social workers facilitated the formation of therapeutic relationships with the 
clients. It provided active listening and allowed them to ventilate feelings via a non-judgemental and respective attitude. It also allowed the participants to express their feelings openly. Moreover, social workers have a close relationship with the informants; thus, they understand the needs and emotional state of the informants and thus offer appropriate care, support and advice. During the interactions, the informants felt valued as the social workers accompanied them and encouraged them to face their problems. Thus, the participants would find the social workers immediately once they had problems or feeling sorrowful due to their strong rapport. For long-term effects, social workers' emotional support and companionship helped drug abusers to understand the meaning of life, regain hope and understand themselves further.

"I have a person to talk to. The social worker is willing to listen to me when I am upset or do not know what to do. She does not judge you and may provide advice or directions. I can choose to follow or not... she really cares about me and understands my needs and difficulties. I think it is difficult to find someone to listen to me and that's why I continue to see her."

"In the process, the social worker's role makes me feel valued, so I have courage to face the problems. He instils hope to me, and I have more chances to understand myself." (Sum)

Social workers would offer suitable and substantial help when the participants feel troubled or confused after taking drugs. They could understand the difficulties that the participants encountered when the participants called for help. They also assisted the participants in discovering their specific needs in their current state, provided useful advices and made referrals to handle their difficulties, such as referring to Chinese medical services that treat the physical sequela of taking drugs.

"Sometimes I do not know what to do or feel confused after taking drugs, I would call the social worker. They will find me and find some suitable services for me...they know I have a bladder problem and will refer Chinese medical services to me." (Man)

\subsection{Revealing Variance towards Nonmandatory Services in CCPSAs}

Variance is revealed by informants in different stages of drug abstinence towards non-mandatory features of services.

Participants in remission from drug abuse felt comfortable with the service flexibility because they could coordinate with social workers about their participation in counselling sessions and various group activities based on mutual agreement. They also felt being respected because the social workers would not restrict their use of drugs or force them to join any activities in the centre, which was considered an advantage over the services in compulsory residential drug rehabilitation centres. This approach motivated them to seek help whenever 
needed and keep using CCPSA services in their remission stage from drug abuse.

“They won't force me to join. It is good and I can join the activities anytime

I like." (Chan)

For participants in first contact with drug abstinence, they acknowledged with more understanding the concept of drug rehabilitation from CCPSAs, but expressed difficulty in the maintenance of its nonmandatory services. They reported to comply with the agreed counselling schedule and join group activities intermittently with default tendency, because they did not have determination to abstain from drugs and were greatly affected by acute withdrawal symptoms in the early stage of drug abstinence. Despite knowing about drug abstinence from social workers in CCPSAs, the participants claimed with difficulty in continuing the use of services without participation restriction.

"I often stood the social worker up. I think it is related to drugs. After taking drugs, I lose motivation because of the withdrawal symptoms. Therefore, I did not show up often. I received CCPSAs service for almost 2 year, I guessed. And I joined the service eight to ten times. Finally, the service was terminated by the centre." (Chan)

\subsection{Encountering Intrapersonal Conflicts When Participating in CCPSAs}

Some of the participants indicated their internal conflicts during drug abstinence in CCPSSAs. Most of them recognized their negative personal characteristics during drug abstinence, including low self-discipline, low self-esteem, low self-confidence in their own abilities and vulnerability to emotional stress.

"Because my self-control is really weak...I couldn't persist in abstinence for a long time, I couldn't stop thinking of drugs..." (Chan)

"Emotions often fluctuate, and sometimes you thought yourself incompetent, because you often remember that you had such an experience (drug abuse)...I don't have the confidence to control what happens afterwards." (Him)

"At that time (abstinence), because I have abused drugs for a long period of time, I easily burst into tears and felt distress." (Yu)

In view of vulnerable characteristics, the participants would easily experience frustration and desperation when facing difficulties, returning to the environment associated with drugs, recalling memories of pleasurable moments from drugs in previous experience and having uncertainty about the future, especially in the community when compared with the period of living in the residential rehabilitation centres. They credited that their frustration posed a great risk on resuming drugs to cope with those unpleasant feelings.

"Will I abstain from drugs? Sometimes I thought to myself, why do I feel very sorrowful when I keep away from drugs, when I am awake?...When I 
was unhappy and I couldn't handle it...I will resume to take drugs as this is the fastest way to cheer up... I have been on drug abstinence for 3 years, and you ask me if I am completely recovered, I will answer you: No!...When frustration comes over, I will think of drugs and even in my dreams at night...I still fight in my internal world every day..." (Sum)

"You will get lost when you are facing lots of stress, because you are accustomed to using drugs as a way to solve problems... or a way to escape from the stress." (Chan)

Nevertheless, throughout their participation in CCPSAs after a period of time, the participants had increased their consideration of future consequence by reflecting on distressing past experiences brought by drugs and recognising the adverse effects that drugs brought in their life. Moreover, some of them do not want to disappoint others' expectations after their initiation of drug abstinence in the service.

"In fact, I had learned from my mistakes. If you fail (in drug abstinence), you have to bear the consequences, CCPSAs let you know the knowledge of detoxification, let you think of the consequences between taking drug or not, etc.... When you clearly think of taking drugs, you will find that a lot of time has been wasted." (Chan)

"My family knows that I have stopped taking drugs for a period of time. If you take drugs again, they will be really disappointed. Do you think you have endured such hardships, would you want to experience again?" (Man)

This antagonistic state repeatedly occurred and thus always caused struggle in the participants' mind during their recovery journey.

\subsection{Expanding Social Network through Integration in Group Activities}

The participants reported that they had happy experiences in group activities. They had strong resonance with the other participants and had a feeling of company. They shared some type of similar experiences with them. They had trust towards the other participants and thus let them build a peer relationship easily, speak of their difficulties and even ask for advice.

"I feel happy when I was joining the group activities in CCPSA. It helps me to build my social network...We have different stories, but in that we can find some similarities. We help each other to get over the difficulties. When one is stuck, I may share my experience on how I solved the situation to him." (Him)

The participants expanded their social circle, which was unimaginable in the past. For example, Man reported that he used to be a gangster, but in the service, he met friends in church. The expanded social network led interviewees create new personal experience. Driven by the new experiences, the participants re- 
flected what they did in the past and realized that they needed change.

"At first, I wanted to find new social groups. And I expand many new social networks from the group activities in CCPSA. For example, I was a gangster in the past, but I knew people from church. They share the gospel with me. I was a worshipper of Guan Yu. It was funny. After listening to Christians' saying, it seemed to make sense. However, I do not believe that there was a great person, I trust it partially now. When I was in prison, I took religious lessons because I was bored and I could stay with people outside the prison which made me feel better than staying with other prisoners. I feel it right in my heart. Although I do not know the reasons for praying, I still pray. The spirit supports like a seed. Whether social workers or group activities are more useful, actually, both are useful. I could not say which one is more important. Actually, both are indispensable. If you only talk with social workers without going to group activities, the social networks would not change and it was ineffective for abstaining from drug abuse. In contrast, if you only go to group activities without talking with social workers, the social networks would not change and it was ineffective for abstaining from drug abuse. That means everything is important. Everything is a seed and CCPSA irrigates the seed for seed germination. The social worker, group activities engaged in my life make me think that it was not good to go to Disco always." (Man)

Although most of the participants reflected that CCPSA group activities helped them expand their new social network, one participant mentioned that he could not integrate into group activities. The participant found difficulty in integrating in a group of people because he had hidden himself.

"I had joined the group activity. The social worker told me to enjoy the activity together with others, but I think...I remember correctly at that time I thought they seemed childish. It was not suitable for me. Because I have been taking drugs for a long time and hidden myself and I imagined that it was a hidden situation. It was difficult for a hidden person to mix in a group of people. I think that I was not suitable for this, and after that I have never joined those group activities." (Chan)

\subsection{Wishing to be a Companion to Other Drug Abusers}

Before seeking service, participants faced various personal and family problems, such as suffering from hereditary diseases (e.g. dystonia or dyslexia) or family history of taking drugs. Thus, the majority of the participants expressed their hopelessness because they felt that they could not change their unfortunate life. Their negative attitude towards life made them immersed in drug abuse. They did not have life satisfaction and were unwilling to change.

"Due to the hereditary disease, I have no confidence since I was young. Also, I was thinking about... Ah...I only had a narrow social circle...I think 
taking drugs can be a medium that allows me to know more people, surrounded by different friends. So I continued to do this. That's it...Why do I keep taking drugs? The main reason is the sudden onset of this hereditary disease. I lose hope and continue a decadent life." (Him)

Joining the group activities with other members in CCPSA provided the participants a chance to reflect on the meaning of life by sharing and discussing their own experience with others. Therefore, they learned from others and changed their negative perspective on life.

"Other drug abusers have different stories but there is something similar. There is nothing special actually. We can support each other to confront obstacles. Sometimes when they cannot pass through the obstacles, I can share my experience with them... I think that you do not need to have something to make your life more beautiful sometimes. Actually, a normal life is fine. It is hard to say, your life can affect me and I can learn from you." (Him)

By joining the activities, the participants were inspired to change their role from being helped to helping others. All the participants participated in peer support services after receiving them. Most of them expressed the intention to help other drug abusers using their own experience. Influencing more drug abusers became their new target in the future, which had changed their attitude towards life. To achieve their goal, they maintained determination of abstinence because they wanted to become role models to drug abusers. They also equipped themselves with knowledge and skills by enrolling in different courses.

"I want to be a Peer Support Worker (volunteer)... I can use my past experience to help drug abusers continually. I really want to use my story to affect people's lives. It becomes my target and gives me confidence to maintain abstinence....My ultimate goal is to be a social worker. I will try hard to achieve this although I think studying and reading are very difficult especially reading English. However, I will try... Moreover, I think that I have spent so many years in drugs, even being sent to prison due to selling illegal drugs. Why cannot I do something meaningful and to help others? I have never done this thing before. I think my action and target make me feel successful. Then, I realize that I am not useless. I can do something that I want to do. It raises my value and keeps me away from drugs." (Sum)

\section{Discussion}

This study identified the drug abusers' experience in participating in CCPSAs during their recovery journey. The findings offered insight into the perception towards and effects brought by the drug rehabilitation services provided by CCPSAs.

Motivation seems to be a common element in rehabilitation programs across cultures. Reference [45] found that drug addicts attach great importance to mo- 
tivational level and believed it was closely related to the outcomes of rehabilitation programs. Reference [46] also discovered a positive correlation between motivation facilitation and abstinence outcome, concluding that it is more effective than coercion in a rehabilitation program. This notion aligns with the present findings that motivation is a common element that drug abusers identify as effective in promoting their recovery. Strengthened motivation is found to be closely related to drug abusers' self-efficacy and sense of control [47], which subsequently leads to actions of change, such as discarding tools for drug use or seeking a job.

Service users gain emotional and substantial support from social workers through individual counselling. Drug abusers seek social workers when they experience confusion, low efficacy and feelings of frustration [48]. Social workers offer companionship, emotion releasing channels and cognitive-emotional counselling. Close therapeutic relationship represents the existence of a trust person to service users. Social workers help change users' thoughts and behaviours for drug abstinence reinforcement by implementing relapse prevention strategies for self-regulation of anxiety symptoms [49] and self-control enhancement [50]. Commitment of drug abstinence with social workers strengthens their determination [51]. Through counselling, service users accept themselves by connecting past events to current life situations [48]. Majority of them have successfully felt better about themselves, strengthened their sense of self-worth, gained personal value and increased self-esteem. They therefore have faith in themselves and promote personal growth and meaning of life in their recovery journey. Moreover, some users achieve sublimation of transforming impulses into socially acceptable actions or behaviour by devoting themselves through a career in helping other fellows who are struggling with drug detoxification and rehabilitation [52].

Regarding substantial support, social workers provide useful advice and referrals according to users' needs and difficulties when users are in bewilderment. This notion matches the finding of [53] that social workers understand users' needs and personality, such that they provide them with a positive initiatory experience. Moreover, social workers' attitude is critical in the referral-making process because their recommendations are associated with increased adherence to such recommendations.

The present work revealed the different opinions towards the nonmandatory services in CCPSAs, which are varied by the stage of abstinence. Informants in remission considered the nonmandatory nature of the services as the advantage that made them feel comfortable to maintain nonmandatory services over compulsory ones.

Limited study found the relationship between nonmandatory services and the service maintenance in various stages of abstinence. A previous study found that compulsory services decrease the clients' satisfaction and result in ineffective outcomes [54]. Hence, nonmandatory services produce better satisfaction and 
thus facilitate service maintenance.

Conversely, the informants expressed that the nonmandatory services demotivated them to join. However, an incongruent result was revealed in a previous study; that is, a high demanding treatment service (e.g. higher commitment) needs a high level of motivation for the clients to stay and enter the treatment [55]. Clients who lack motivation or readiness to the treatment service drop out [56].

Another previous study showed that treatment engagement is multifactorial [57], such as in terms of drug treatment history and drug use [55]. Thus, the nature of the service is not the only factor that contributes to disengagement.

This study found that the majority of the informants encountered ongoing ambivalence over the maintenance of drug abstinence.

In view of the vulnerability of stress among drug abusers, they are usually overwhelmed by the influence of a drug craving environment and their negative intrapersonal state when experiencing difficulties in adapting to the community, which poses a significant risk of a relapse situation. This finding is in congruence with previous studies [9] [12] [13] further explained that when actual perceived stress and drug incentives brought by environmental factor goes beyond drug abusers' coping skills and abstinent effort, drug abusers may resort to taking drugs to regain previous desired and pleasurable effects brought by those drugs and lessen their stress from reality.

However, drug abusers have learnt to take their responsibilities on their rehabilitation journey. During the period of receiving services from the CCPSAs, their consideration of future consequences has increased. They have developed knowledge and have first-hand experiences from the considerable adverse effects brought by drug abuse. Moreover, some of them regard drug abstinence as a difficult but meaningful process because they have to exert considerable effort to remain abstinent and overcome struggles and difficulties. As a result, they do not want to make futile efforts, re-experience the vicious cycle and disappoint others' expectations, especially their family members and trusted social workers. Some previous studies have similar interpretations that community rehabilitation programmes enable their members to build self-resilience and acquire responsibilities, as well as abilities to re-establish positive relationships with others by engaging in positive activities to develop a better social connection and support a return to "normality" [10] [58]. Drug abusers feel being valued and regain a sense of role commitment in the society, which help them sustain community recovery.

CCPSAs provide a platform for their participants to expand their social network and thus gain social support and benefit for their recovery. This study found that the participants had a great resonance with their peers who had similar experiences with them. Trustful peer relationships among the CCPSA participants were built during group activities. Such relationships supported them when they encountered obstacles, bringing a positive influence on recovery. Par- 
ticipants also mentioned that they had happy experiences in group activities. The result is congruent with the previous literature review. As a significant type of group treatment in CCPSAs, peer support group has been found to help reduce feelings of shame due to sharing similar experiences with peers, enhance social support and increase satisfaction with the overall drug treatment experience [28]. A previous study also showed that an increased period of drug abstinence could be benefited from peer support groups [32].

This study also found that the participants created new experiences by expanding their new social network by joining various group activities organized by CCPSAs. This notion matches the finding of [1] that clients in CCPSAs who engage in to different group activities develop their interests by exploring new personal experiences. The participants also mentioned that they decided to change, driven by the new experience and reflection towards their past personal life. This finding is congruent with a research study by [59] that individuals who experience drug use disorder hold positive attitudes towards drug abstinence because of the larger social networks. Individuals demonstrate a positive attitude towards the recovery process, which motivates them to change and maintain drug abstinence.

One participant reported that the group activities could not help him expand his social circle because he hid himself at that time. Chronic drug users demonstrate deficits in social functioning. Reference [60] reported that the duration of cocaine use is associated with deficits in empathy and reduced social contacts, leading to reduced chances for cocaine users to learn and practice their social abilities and an increase in cocaine use. For the informant's case in the present work, the maladaptation to group activities was attributed to chronic substance use. To break the vicious cycle, social skills training is recommended to be intensified by role playing and giving feedback in individual counselling sessions. This method can increase participants' readiness to join a group activity and interact with others.

In the previous part of the result, some participants were inspired to change their role from being helped to helping others. They participated in peer support services after receiving them. By sharing and discussing their experiences with others, they reflected on the meaning of life. The participants demonstrated a positive attitude towards their past experience and future. They were willing to share their drug history and experience with others. Reference [33] explained that the reduction of feeling shame was a major positive change after receiving the treatment. In addition, they had a new target, that is, being a role model to the other drug abusers. This target motivated them to maintain drug abstinence, rebuild their life by learning new knowledge and skills and actively engage in the community. As the previous literature review mentioned, types of CCPSA service could reshape the participants' maladaptive emotions and perceptions [31], improve their self-efficacy in coping [33] and attain a longer period of abstinence [32]. The wish of our participants proved that the community-based drug 
rehabilitation services provided by CCPSAs could effectively deliver positive influences on life.

\section{Implications}

\subsection{Healthcare Service Provider}

As professional healthcare service providers, nurses play a vital role in collaboration with community service organizations that provide advanced and coordinated medical support to substance abusers. Empathy is widely considered a core competence of mental health nurses [61]. It involves nurses being aware of and understanding the "inner world" of patients [62]. Unfortunately, some nurses may have negative opinions of people with substance use. Reference [63] found that among 180 Taiwanese mental health nurses, negative attitudes against substance abusers are more intense than that against patients with schizophrenia and major depression. Reference [64] conducted a systematic review that includes articles published in Western countries in a decade. They concluded that diminished empathy towards substance abusers is common and has resulted in sub-optimal health outcomes. Therefore, presenting substance abusers' experience to mental health nurses can facilitate the development of empathy.

\subsection{Service Modification}

At the organization level, CCPSAs can strengthen their services to users who are in first contact with drug abstinence because they demonstrate relatively high default tendency to CCPSAs' nonmandatory services. The staff can discuss with the new clients about their expectations about the service and come up with an agreement on the goals of using the services at service initiation. To increase clients' internal motivation and further their involvement and retention, motivational interviewing sessions can be useful. Furthermore, the staff can initially approach and discuss with the clients who have a history of missed appointments or early drop out from services the reasons for their behaviour in a non-judgmental, problem-solving manner. If clients experience physical withdrawal symptoms, then a short "therapeutic break" can be discussed mutually with the expectation or scheduling a return to service should be required.

\subsection{Public Education}

In the community level, public education about CCPSAs is needed to encourage drug abusers to seek help and facilitate public understanding of drug rehabilitation services. Public education can be achieved by sharing successful featured stories on mass media, such as newspapers, news magazines and television. The journey of drug abusers in achieving abstinence demonstrates the importance and efficacy of drug rehabilitation services and CCPSAs and, more importantly, promotes public acceptance and facilitates the reintegration of drug abusers into society. 


\section{Conclusions}

This study explores the experience of drug abusers in using community drug rehabilitation services, especially about their service perception and effects brought by the services. A sense of accompaniment and support provided by social and peer support workers who are involved in various services are revealed as the core experience for the participants in this study. However, fleeting participation is shown among participants in the early drug abstinence stage under various challenges in the use of CCPSA services and nonmandatory nature of services.

Drug abusers participate in community-based drug rehabilitation services on their own. Motivation to drug abstinence is of paramount. To maximize the efficacy of community drug rehabilitation services in their drug abstinence journey, different parts of society, including healthcare service providers, service providers and media, should consider collaboration for the sake of promoting the wellbeing of drug abusers living in the community.

\section{Acknowledgements}

The authors would like to thank all the staff of CCPSAs and the participants of this study.

\section{Conflicts of Interest}

The authors declare no conflicts of interest regarding the publication of this paper.

\section{References}

[1] Narcotic Division (2019) Three-Year Plan on Drug Treatment and Rehabilitation Services in Hong Kong (2018-2020).

https://www.nd.gov.hk/pdf/three_year_plan_2018_2020_final_en.pdf

[2] Census and Statistics Department (2016) Drug Abuse Situation in Hong Kong in 2015. https://www.statistics.gov.hk/pub/B71608FC2016XXXXB0100.pdf

[3] Kwok, S.I., Lo, T.W., Lam, S.H.P. and Lee, G.K.W. (2018) Hidden Drug Abuse in Hong Kong: From Social Acquaintance to Social Isolation. Frontiers in Psychiatry, 9, 457. https://doi.org/10.3389/fpsyt.2018.00457

[4] Narcotic Division (2019) Treatment and Rehabilitation. https://www.nd.gov.hk/text/en/treat/index.htm

[5] World Health Organization (2019) Substance Abuse. https://www.who.int/topics/substance_abuse/en

[6] Fox, H.C., Hong, K.I.A., Siedlarz, K. and Sinha, R. (2008) Enhanced Sensitivity to Stress and Drug/Alcohol Craving in Abstinent Cocaine-Dependent Individuals Compared to Social Drinkers. Neuropsychopharmacology, 33, 796. https://doi.org/10.1038/sj.npp.1301470

[7] Sinha, R. (2007) The Role of Stress in Addiction Relapse. Current Psychiatry Reports, 9, 388-395. https://doi.org/10.1007/s11920-007-0050-6

[8] Sinha, R., Lacadie, C., Skudlarski, P., Fulbright, R.K., Rounsaville, B.J., Kosten, T.R. and Wexler, B.E. (2005) Neural Activity Associated with Stress-Induced Cocaine Craving: A Functional Magnetic Resonance Imaging Study. Psychopharmacology, 
183, 171-180. https://doi.org/10.1007/s00213-005-0147-8

[9] Appiah, R., Danquah, S.A., Nyarko, K., Ofori-Atta, A.L. and Aziato, L. (2017) Precipitants of Substance Abuse Relapse in Ghana: A Qualitative Exploration. Journal of Drug Issues, 47, 104-115. https://doi.org/10.1177/0022042616678612

[10] Fredericks, J. and Samuel, E. (2014) Drugs and Recovery: A Qualitative Study in Atlantic Canada. American International Journal of Social Science, 3, 28-34.

[11] Ibrahim, F. and Kumar, N. (2009) Factors Affecting Drug Relapse in Malaysia: An Empirical Evidence. Asian Social Science, 5, 37-44. https://doi.org/10.5539/ass.v5n12p37

[12] Ramo, D.E. and Brown, S.A. (2008) Classes of Substance Abuse Relapse Situations: A Comparison of Adolescents and Adults. Psychology of Addictive Behaviors, 22, 372. https://doi.org/10.1037/0893-164X.22.3.372

[13] Shafiei, E., Hoseini, A.F., Bibak, A. and Azmal, M. (2014) High Risk Situations Predicting Relapse in Self-Referred Addicts to Bushehr Province Substance Abuse Treatment Centers. International Journal of High Risk Behaviors \& Addiction, 3, e16381. https://doi.org/10.5812/ijhrba.16381

[14] Lam, C.S., Tsang, H.W.H., Corrigan, P.W., Lee, Y.T., Angell, B., Shi, K., Larson, J.E., et al. (2010) Chinese Lay Theory and Mental Illness Stigma: Implications for Research and Practices. The Journal of Rehabilitation, 76, 35-40.

[15] Lloyd, C. (2013) The Stigmatization of Problem Drug Users: A Narrative Literature Review. Drugs: Education, Prevention and Policy, 20, 85-95. https://doi.org/10.3109/09687637.2012.743506

[16] Sinha, R. (2008) Chronic Stress, Drug Use, and Vulnerability to Addiction. Annals of the New York Academy of Sciences, 1141, 105. https://doi.org/10.1196/annals.1441.030

[17] Ai, Y.T., Shen, H.Y. and Tao, Y. (2018) A Qualitative Analysis of the Psychological Factors of Relapsing Females. Advances in Social Science, Education and Humanities Research, 233, 1525-1527. https://doi.org/10.2991/iccessh-18.2018.333

[18] Lander, L., Howsare, J. and Byrne, M. (2013) The Impact of Substance Use Disorders on Families and Children: From Theory to Practice. Social Work in Public Health, 28, 194-205. https://doi.org/10.1080/19371918.2013.759005

[19] The Hong Kong University (2011) A Study on Drug Abuse among Youths and Family Relationships. Legislative Council of the Hong Kong Special Administrative Region.

https://www.legco.gov.hk/yr11-12/chinese/panels/ws/papers/ws0312cb2-1546-1-ec. pdf

[20] Parolin, M., Simonelli, A., Mapelli, D., Sacco, M. and Cristofalo, P. (2016) Parental Substance Abuse as an Early Traumatic Event. Preliminary Findings on Neuropsychological and Personality Functioning in Young Drug Addicts Exposed to Drugs Early. Frontiers in Psychology, 7, 887. https://doi.org/10.3389/fpsyg.2016.00887

[21] Solis, J.M., Shadur, J.M., Burns, A.R. and Hussong, A.M. (2012) Understanding the Diverse Needs of Children Whose Parents Abuse Substances. Current Drug Abuse Reviews, 5, 135-147. https://doi.org/10.2174/1874473711205020135

[22] Marotta, P. (2017) Exploring Relationships between Delinquent Peer Groups, Participation in Delinquency, Substance Abuse, and Injecting Drug Use among the Incarcerated: Findings from a National Sample of State and Federal Inmates in the United States. Journal of Drug Issues, 47, 320-339.

https://doi.org/10.1177/0022042617690234 
[23] Wongtongkam, N., Ward, P.R., Day, A. and Winefield, A.H. (2014) The Influence of Protective and Risk Factors in Individual, Peer and School Domains on Thaiadolescents Alcohol and Illicit Drug Use: A Survey. Addictive Behaviors, 39, 1447-1451. https://doi.org/10.1016/j.addbeh.2014.05.026

[24] Andreas, D., Ja, D.Y. and Wilson, S. (2010) Peers Reach Out Supporting Peers to Embrace Recovery (PROSPER): A Center for Substance Abuse Treatment Recovery Community Services Program. Alcoholism Treatment Quarterly, 28, 326-338. https://doi.org/10.1080/07347324.2010.488538

[25] Jason, L.A., Davis, M.I. and Ferrari, J.R. (2007) The Need for Substance Abuse After-Care: Longitudinal Analysis of Oxford House. Addictive Behaviours, 32, 803-818. https://doi.org/10.1016/j.addbeh.2006.06.014

[26] Hong Kong Medical Association (HKMA) (2011) Manage of Drug Abuse Patients for Family Doctors Part II.

https://www.nd.gov.hk/pdf/management_of_drug_abuse_patients_for_family_doct ors/part_ii.pdf

[27] Brooks, F. and McHenry, B. (2009) A Contemporary Approach to Substance Abuse and Addiction Counseling: A Counselor's Guide to Application and Understanding. American Counseling Association, Alexandria.

[28] Reif, S., Braude, L., Lyman, D.R., Dougherty, R.H., Daniels, A.S., Ghose, S.S., Delphin-Rittmon, M.E., et al. (2014) Peer Recovery Support for Individuals with Substance Use Disorders: Assessing the Evidence. Psychiatric Services, 65, 853-861. https://doi.org/10.1176/appi.ps.201400047

[29] Miller, G. (2014) Learning the Language of Addiction Counseling. 4th Edition, John Wiley \& Sons Inc., Hoboken.

[30] Petrova, H.A., Kytianova, I.P. and Kozyakov, R.V. (2015) Social and Personal Factors of Stable Remission for People with Drug Addictions. Psychology in Russia: State of the Art, 8, 126-138. https://doi.org/10.11621/pir.2015.0411

[31] McHugh, K., Hearon, B. and Otto, M. (2010) Cognitive Behavioral Therapy for Substance Use Disorders. Psychiatric Clinics of North America, 33, 511-525. https://doi.org/10.1016/j.psc.2010.04.012

[32] United Nations Office of Drug and Crime (UNODC) (2002) Contemporary Drug Abuse Treatment-A Review of the Evidence Base. https://www.unodc.org/docs/treatment/contemporary_drug_abuse_treatment.pdf

[33] Tracy, K. and Wallace, S. (2016) Benefits of Peer Support Groups in the Treatment of Addiction. Substance Abuse and Rehabilitation, 7, 143-154. https://doi.org/10.2147/SAR.S81535

[34] Roessler, K.K. (2010) Exercise Treatment for Drug Abuse-A Danish Pilot Study. Scandinavian Journal of Public Health, 38, 664-669. https://doi.org/10.1177/1403494810371249

[35] Aletraris, L., Paino, M., Edmond, M.B., Roman, P.M. and Bride, B.E. (2014) The Use of Art and Music Therapy in Substance Abuse Treatment Programs. Journal of Addictions Nursing, 25, 190. https://doi.org/10.1097/JAN.0000000000000048

[36] Fossey, E., Harvey, C., McDermott, F. and Davidson, L. (2002) Understanding and Evaluating Qualitative Research. Australian and New Zealand Journal of Psychiatry, 36, 717-732. https://doi.org/10.1046/j.1440-1614.2002.01100.x

[37] Patton, M.Q. (2002) Qualitative Research and Evaluation Methods. 3rd Edition, Sage Publications, Thousand Oaks.

[38] Substance Abuse and Mental Health Services Administration (2019) Treatment Ep- 
isode Data Set (TEDS): 2017. Admissions to and Discharges from Publicly-Funded Substance Use Treatment, Rockville.

https://www.samhsa.gov/data/sites/default/files/cbhsq-reports/TEDS-2017.pdf

[39] DiCicco-Bloom, B. and Crabtree, B.F. (2006) The Qualitative Research Interview. Medical Education, 40, 314-318. https://doi.org/10.1111/j.1365-2929.2006.02418.x

[40] Jamshed, S. (2014) Qualitative Research Method-Interviewing and Observation. Journal of Basic and Pharmacy, 5, 87-88. https://doi.org/10.4103/0976-0105.141942

[41] Tessier, S. (2012) From Field Notes, to Transcripts, to Tape Recordings: Evolution or Combination? International Journal of Qualitative Methods, 11, 446-460. https://doi.org/10.1177/160940691201100410

[42] Braun, V. and Clarke, V. (2006) Using Thematic Analysis in Psychology. Qualitative Research in Psychology, 3, 77-101. https://doi.org/10.1191/1478088706qp063oa

[43] King, N. (2004) Using Templates in the Thematic Analysis of Text. Essential Guide to Qualitative Methods in Organizational Research, Sage, Thousand Oaks, 256-270. https://doi.org/10.4135/9781446280119.n21

[44] Saldana, J. (2013) The Coding Manual for Qualitative Researchers. 2nd Edition, Sage, Los Angeles.

[45] Gideon, L. (2010) Drug Offenders' Perceptions of Motivation: The Role of Motivation in Rehabilitation and Reintegration. International Journal of Offender Therapy and Comparative Criminology, 54, 597-610. https://doi.org/10.1177/0306624X09333377

[46] Wolfe, S., Kay-Lambkin, F., Bowman, J. and Childs, S. (2013) To Enforce or Engage: The Relationship between Coercion, Treatment Motivation and Therapeutic Alliance within Community-Based Drug and Alcohol Clients. Addictive Behaviors, 38, 2187-2195. https://doi.org/10.1016/j.addbeh.2013.01.017

[47] Peterson, P., Baer, J., Wells, E., Ginzler, J. and Garrett, S. (2006) Short-Term Effects of a Brief Motivational Intervention to Reduce Alcohol and Drug Risk among Homeless Adolescents. Psychology of Addictive Behaviors, 20, 254-264. https://doi.org/10.1037/0893-164X.20.3.254

[48] O’Sullivan, D., Blum, J.B., Watts, J. and Bates, J.K. (2015) SMART Recovery: Continuing Care Considerings for Rehabilitation Counselors. Rehabilitation Counseling Bulletin, 58, 203-216. https://doi.org/10.1177/0034355214544971

[49] Brady, K.T., Haynes, L.F., Hartwell, K.J. and Killeen, T.K. (2013) Substance Use Disorders and Anxiety: A Treatment Challenge for Social Workers. Social Work in Public Health, 28, 407-423. https://doi.org/10.1080/19371918.2013.774675

[50] Straussner, S.L.A. (2012) Clinical Treatment of Substance Abusers: Past, Present and Future. Clinical Social Work Journal, 40, 127-133.

https://doi.org/10.1007/s10615-012-0387-0

[51] Ehman, A.C. and Gross, A.M. (2019) Acceptance and Commitment Therapy and Motivational Interviewing in the Treatment of Alcohol Use Disorder in a College Woman: A Case Study. Clinical Case Studies, 18, 36-53. https://doi.org/10.1177/1534650118804886

[52] Trevithick, P. (2011) Understanding Defences and Defensiveness in Social Work. Journal of Social Work Practice, 25, 389-412. https://doi.org/10.1080/02650533.2011.626642

[53] Dennis, C.B. and Davis, T.D. (2017) Enhancing the Referral-Making Process to 12-Step Programs: Strategies for Social Workers. Research on Social Work Practice, 27, 423-433. https://doi.org/10.1177/1049731515586582 
[54] Kelly, J., Finney, J. and Moos, R. (2005) Substance Use Disorder Patients Who Are Mandated to Treatment: Characteristics, Treatment Process, and 1- and 5-Year Outcomes. Journal of Substance Abuse Treatment, 28, 213-223. https://doi.org/10.1016/j.jsat.2004.10.014

[55] Melnick, G., Hawke, J. and De Leon, G. (2014) Motivation and Readiness for Drug Treatment: Differences by Modality and Special Populations. Journal of Addictive Diseases, 33, 134-147. https://doi.org/10.1080/10550887.2014.909700

[56] Palmer, R.S., Murphy, M.K., Piselli, A. and Ball, S.A. (2009) Substance User Treatment Dropout from Client and Clinician Perspectives: A Pilot Study. Substance Use \& Misuse, 44, 1021-1038. https://doi.org/10.1080/10826080802495237

[57] Shim, R., Compton, S., Zhang, M., Roberts, T., Rust, S. and Druss, K. (2017) Predictors of Mental Health Treatment Seeking and Engagement in a Community Mental Health Center. Community Mental Health Journal, 53, 510-514.

https://doi.org/10.1007/s10597-016-0062-y

[58] Harrison, R., Hout, M.C.V., Cochrane, M., Eckley, L., Noonan, R., Timpson, H. and Sumnall, H. (2018) Experiences of Sustainable Abstinence-Based Recovery: An Exploratory Study of Three Recovery Communities (RC) in England. International Journal of Mental Health and Addiction, 18, 640-665. https://doi.org/10.1007/s11469-018-9967-8

[59] Mowbray, O. and Scott, J. (2015) The Effect of Drug Use Disorder Onset, Remission or Persistence on an Individual's Personal Social Network. The American Journal on Addictions, 24, 427-434. https://doi.org/10.1111/ajad.12224

[60] Preller, K.H., Hulka, L.M., Vonmoos, M., Jenni, D., Baumgartner, M.R., Seifritz, E. and Quednow, B.B. (2014) Impaired Emotional Empathy and Related Social Network Deficits in Cocaine Users. Addiction Biology, 19, 452-466. https://doi.org/10.1111/adb.12070

[61] Williams, J. and Stickley, T. (2010) Empathy and Nurse Education. Nurse Education Today, 30, 752-755. https://doi.org/10.1016/j.nedt.2010.01.018

[62] Galvin, K. and Todres, L. (2011) Research Based Empathic Knowledge for Nursing: A Translational Strategy for Disseminating Phenomenological Research Findings to Provide Evidence for Caring Practice. International Journal of Nursing Studies, 48, 522-530. https://doi.org/10.1016/j.ijnurstu.2010.08.009

[63] Hsiao, C., Lu, H. and Tsai, Y. (2015) Factors Influencing Mental Health Nurses' Attitudes towards People with Mental Illness. International Journal of Mental Health Nursing, 24, 272-280. https://doi.org/10.1111/inm.12129

[64] van Boekel, L., Brouwers, E., van Weeghel, J. and Garretsen, H. (2013) Stigma among Health Professionals towards Patients with Substance Use Disorders and Its Consequences for Healthcare Delivery: Systematic Review. Drug and Alcohol Dependence, 131, 23-35. https://doi.org/10.1016/j.drugalcdep.2013.02.018 